CASA, Vol.9 n.1, julho de 2011

Cadernos de Semiótica Aplicada

Vol. 9.n.1, julho de 2011

Publicação SEMESTRAL

ISSN: $1679-3404$

\title{
O ESTUDO SEMIÓTICO DA POESIA ${ }^{1}$
}

THE SEMIOTIC STUDY OF POETRY

\author{
Dayane Celestino de Almeida \\ USP - Universidade de São Paulo
}

\begin{abstract}
RESUMO: Nos anos 70, foi publicada a única obra inteiramente dedicada à Semiótica Poética no âmbito da Escola de Paris: o livro Ensaios de semiótica poética (1975), organizado por A. J. Greimas. Porém, durante todo o período de emergência da Linguística estruturalista, diversos outros trabalhos foram dedicados ao assunto. Assim, o artigo que propomos é norteado por dois objetivos: o primeiro, mais geral, é reunir, em um único texto, várias questões importantes a respeito da semiótica poética, dispersas ao longo da literatura sobre o tema; o segundo, mais específico, é analisar o poema "O prestidigitador", do poeta brasileiro contemporâneo Paulo Henriques Britto, sob a perspectiva da semiótica francesa.
\end{abstract}

PALAVRAS-CHAVE: Poesia; Semiótica; Linguística; Greimas; Jakobson.

ABSTRACT: In the 1970s, A.J. Greimas organized the only work entirely devoted to the Poetic Semiotics in the School of Paris: Ensaios de Semiótica Poética (1975). However, throughout the emergent period of the Structuralist Linguistics, several other papers on that theme were developed. Thus, the study proposed is guided by two goals: the first one is to gather several matters regarding poetic semiotics, scattered throughout the literature on the subject; the second one is to analyze the poem "O prestidigitador", by Paulo Henriques Britto, a contemporary Brazilian poet, through the French semiotics point of view.

KEYWORDS: Poetry; Semiotics; Linguistics; Greimas; Jakobson.

\section{Introdução}

El poema no tiene objeto o referencia exterior; la referencia de una palabra es otra palabra. Así, el problema de la significación de la poesia se esclarece apenas se repara en que el sentido no está fuera sino dentro del poema: no en lo que dicen las palabras, sino en aquello que se dicen entre ellas.

(Octavio Paz)

\footnotetext{
${ }^{1}$ Este trabalho foi realizado com o auxílio do CNPq.
} 
Desde que, em meados do século XX, os estudos linguísticos ultrapassaram a dimensão da frase e passaram a ocupar-se também da dimensão textual e discursiva, uma série de teorias do texto e do discurso têm sido desenvolvidas e utilizadas para dar conta desse rumo de investigação no âmbito das ciências da linguagem. A semiótica francesa (ou greimasiana) é uma dessas teorias, e é em seu quadro teórico que se desenvolve o nosso trabalho.

Herdeira da linguística saussuriana, a semiótica de Greimas destaca-se por ser concebida como uma teoria da significação, que busca desvendar os mecanismos de construção (ou geração) do sentido nos diversos tipos de texto, postulando que os discursos são redes de relações e que, a partir dessas, o sentido é gerado. Ou seja, o sentido está não no signo a priori, mas nas relações que um signo estabelece com o outro dentro de cada texto. Além de ser uma teoria da significação, a semiótica é também uma metodologia de análise de textos, entendendo como tais não apenas as manifestações verbais, mas também aquelas em outras linguagens. Outros estudos linguísticos que estão em suas bases são aqueles desenvolvidos por Hjelmslev e Jakobson.

Boa parte dos estudos literários tem como fio condutor uma investigação cujo ponto de partida é o exame "externo" do texto, ou "de fora para dentro". Em outras palavras, a análise vale-se de dados sócio-históricos ou até mesmo biográficos, frequentemente mais interessada em compreender os contextos do que os textos em si. Traçando um percurso inverso e complementar a esse, a semiótica examina o texto "de dentro para fora", esforçando-se por construir, antes de mais nada, uma escrupulosa descrição "interna" do texto, para, só então, ir em busca das suas conexões intertextuais ou contextuais. Assim, a semiótica considera que o texto é um todo de significação que "produz em si mesmo as condições contextuais de sua leitura" (BERTRAND, 2003, p. 23). Por meio de uma análise semiolinguística, acreditamos que conseguimos chegar mais perto de revelar o que faz do poema um poema e não um texto filosófico, social, biográfico, etc. Em nosso trabalho, pretendemos realizar "a exploração dos procedimentos linguísticos que provocam o efeito de poeticidade" (BALDAN, 1994, p. 249, grifo nosso).

Apesar do crescimento considerável dos estudos semióticos, ainda são relativamente poucas as análises de textos literários (e, muito em particular, de poesia) que se valem desse instrumental teórico. Uma das razões dessa subutilização é a complexidade teórica. Conforme Tatit (2001, p. 11),

[...] os recursos aplicativos da disciplina são, em geral, substituídos por métodos menos rigorosos que atingem resultados imediatos, de cunho interpretativo ou parafrástico, descuidando-se totalmente da construção global de um modelo que subsista à descrição particular de cada texto.

Em se tratando especificamente dos estudos sobre Semiótica e Poesia, o que se vê é uma lacuna considerável, sendo que o livro organizado por Greimas (1975 [1972]), Ensaios de semiótica poética, é a única obra publicada inteiramente dedicada ao assunto. Nela, procurou-se definir o objeto da semiótica poética e levantar as questões relevantes para a análise dos textos poéticos. Os estudos de Roman Jakobson sobre poesia também são fundamentais para o exame desses textos, uma vez que propõem uma análise estrutural dos poemas e a descrição detalhada de diversos níveis linguísticos e suas relações na construção do sentido. Atualmente, encontramos estudos desenvolvidos principalmente por Claude Zilberberg. Em um deles, o autor (ZILBERBERG, 2006, p. 197) faz o seguinte comentário: 
O estudo semiótico dos textos poéticos aparenta estar, já há algum tempo 'em pane'. Passada a época marcada pelas contribuições de R. Jakobson [...], a publicação dos Ensaios de Semiótica Poética sob a direção de A. J. Greimas, outros temas absorveram a atenção. Teria sido um entusiasmo passageiro, fadado ao abandono? Ou incertezas metodológicas oriundas do recurso simultâneo ao apriorismo e ao método indutivo, que acarreta o 'caso a caso'? Deixemos essas interrogações como estão, e admitamos apenas que os progressos da semiótica devem, de direito, trazer benefícios à abordagem semiótica dos textos poéticos.

Dessa forma, nosso trabalho se justifica ao contribuir para a expansão dos estudos semióticos de poesia e se insere no campo da Semiótica Poética. Greimas e Courtés (1983, p. 339) lembram que o termo poética designa, em sentido corrente, não apenas o estudo da poesia, mas também os estudos sobre a prosa, ou uma "teoria geral das obras literárias". Os autores afirmam, ainda, que o fato poético seria "um domínio semiótico autônomo fundamentado no reconhecimento de articulações paralelas e correlativas que envolvem os dois planos (a expressão e o conteúdo) do discurso ao mesmo tempo" (p. 340).

Tal afirmação nos faz pensar em outros tipos de textos, na pintura, por exemplo, como poéticos. Neste trabalho, no entanto, sempre que nos referirmos à poética ou à semiótica poética, estaremos falando apenas do estudo de poesia.

Assim, o trabalho que propomos é norteado por dois objetivos: o primeiro, mais geral, é reunir, em um único texto, várias questões importantes a respeito da semiótica poética, dispersas ao longo da literatura sobre o tema; o segundo, mais específico, é analisar o poema "O prestidigitador" (Trovar Claro), de Britto (1997), sob a perspectiva da semiótica francesa, preenchendo a lacuna que há no que diz respeito a análises aprofundadas dos poemas de um importante poeta da atualidade, cuja obra, apesar de bastante comentada, carece de trabalhos críticos que se debrucem mais atentamente sobre os textos, analisando-os pormenorizadamente, já que mesmo aqueles trabalhos de maior fôlego concentram seus esforços em explicar pontos pertinentes a uma poética "geral" desse autor, fazendo apenas comentários sobre os textos em si, ficando, pois, um espaço a completar no que diz respeito à análise minuciosa, "verticalizada" dos textos.

Nossa investigação é tributária de trabalhos de alguns linguistas, tais como Ferdinand de Saussure, em seu estudo sobre os anagramas, ${ }^{2}$ e Roman Jakobson, com seus estudos estruturais e gramaticais de poesia. ${ }^{3}$ Ademais, percorremos alguns estudos de semioticistas, principalmente aqueles presentes em Ensaios de semiótica poética, a coletânea que, como já dissemos, foi organizada por Greimas (1975).

A semiótica postula, na esteira de Hjelmslev (2003), que um texto é um signo e que esse por sua vez é "um todo formado por uma expressão e um conteúdo" (p. 53). Um conteúdo é, sempre, manifestado por uma expressão. Num primeiro momento, os semioticistas preocuparam-se apenas com os estudos do plano do conteúdo, concebendo-o, metodologicamente, sob a forma de um "percurso gerativo do sentido" (GREIMAS; COURTÉS, 1983), talvez o maior legado da semiótica greimasiana. De acordo com Tatit (2004, p. 206), “[...] a semiótica dissocia o plano do conteúdo do plano da expressão e estudaos separadamente até reunir condições conceituais para relacionar categorias de ambos os planos e então compreender melhor o mecanismo geral da semiose".

\footnotetext{
${ }^{2}$ Cf. Starobinski (1978).

${ }^{3}$ Cf. Jakobson (1962, 1969, 1990, 2004).
} 
Com o passar dos anos, então, a semiótica passou a considerar também questões relativas ao plano da expressão, complementando a análise do conteúdo. Essa direção da semiótica é extremamente importante para os estudos de textos literários, especialmente no que diz respeito à poesia, na medida em que o discurso da poesia mobiliza não apenas os recursos do significado, mas também os do significante, em seu grau máximo.

Assim, no estudo de poemas, torna-se imprescindível uma análise rigorosa do plano da expressão, pois "a compreensão de um texto com função estética exige que se entenda não somente o conteúdo, mas também o significado dos elementos da expressão" (FIORIN, 2008, p. 57).

O trabalho minucioso com o plano da expressão é um dos fatores que confere especificidade aos textos poéticos. Nas palavras de Fiorin (2008, p. 45) “a primeira característica do texto literário é a relevância do plano da expressão, que, nele, serve não apenas para veicular conteúdos, mas para recriá-los em sua organização".

Ao encontro de tais afirmações vai a definição de Jakobson (s.d., p. 41, tradução nossa) para poesia: "o enunciado no qual a ênfase é colocada na expressão". "

Por isso, na análise que apresentamos adiante, foi dada bastante atenção a tal plano, procurando mostrar como se dá a sua construção e, sempre que possível, qual é sua relação com o plano do conteúdo, bem como quais as relações semissimbólicas existentes (há semissimbolismo quando categorias do plano da expressão se correlacionam a categorias do plano do conteúdo).

\section{Semiótica e Poesia}

O poema - essa hesitação prolongada entre o som e o sentido.

(Paul Valéry).

Aqui pretendemos traçar um breve panorama dos estudos relacionados ao campo da Semiótica Poética, a fim de, como já dito na Introdução, reunir, em um único trabalho, algumas referências significativas a respeito desse tema, bem como apresentar os pressupostos teóricos específicos que nos serviram de norte. Longe de fazer uma explanação minuciosa e uma exploração profunda dos textos percorridos, procuramos, simplesmente, apontar pontos essenciais que permearam as reflexões por nós realizadas.

Nos anos 70, foi publicada a única obra inteiramente dedicada à Semiótica Poética, no âmbito da Escola de Paris: o livro Ensaios de semiótica poética (1975), organizado por Greimas, que conta com ensaios de pesquisadores importantes no campo da semiótica, tais como Jean-Claude Coquet, Jacques Geninasca, Claude Zilberberg, Teun A. Van Dijk, Julia Kristeva, François Rastier, entre outros. As correlações entre os diversos níveis linguísticos perpassam todo o livro.

No primeiro capítulo dessa obra, intitulado "Por uma teoria do discurso poético", Greimas procura definir o objeto da Semiótica Poética. Para tanto, ele trata da questão do fato poético, enfatizando que ele não é restrito aos textos verbais, mas sim "indiferente à linguagem em que é produzido" (GREIMAS, 1975, p. 12). Greimas diz, ainda, que o fato poético é percebido intuitivamente, e sua especificidade estaria calcada em uma organização estrutural que seja peculiar ao discurso produzido. Tal organização seria dada pela correlação do plano da expressão e do plano do conteúdo, a qual seria o postulado da semiótica poética proposta pelo semioticista e sua escola.

\footnotetext{
${ }^{4}$ Texto original: "énoncé dans lequel l'accent est mis sur l'expression".
}

Disponível em: http://seer.fclar.unesp.br/casa 
Apesar da definição de Greimas para fato poético, estendendo o conceito a diversos tipos de textos, em nosso trabalho, quando nos referirmos ao "poético", estaremos tratando apenas de textos verbais literários, mais especificamente de poemas.

Greimas enxergava duas direções de pesquisa que a Semiótica Poética deveria seguir. A primeira seria "fundamentar e justificar os processos de reconhecimento das articulações" entre os dois níveis (da expressão e do conteúdo), já que o discurso poético projeta-se ao mesmo tempo nos dois planos (GREIMAS, 1975, p. 12). A segunda direção apontada por ele diz respeito ao estabelecimento de uma "tipologia das correlações possíveis entre os planos da expressão e do conteúdo" (p. 13).

Em se tratando apenas do plano da expressão, Greimas ressalta, porém, que faltam "modelos de articulação fêmicos estimulantes" (p. 21). Em outras palavras, faltaria uma gramática capaz de dar conta da organização geral do "discurso fonético" (p. 21) em poesia. Isso não impede, porém, que o analista busque reconhecer, em cada texto, a organização de tal plano, com suas equivalências e descontinuidades, bem como sua relação com o conteúdo.

É impossível falar de uma Semiótica Poética sem nos remeter aos estudos de poesia realizados por Roman Jakobson. O célebre estudo "Linguística e Poética" (1969) define a questão-objeto da Poética: "Que é que faz de uma mensagem verbal uma obra de arte?” (p. 118). Ademais, propõe que a Poética seja parte integrante da Linguística, conforme citação a seguir: "A Poética trata dos problemas da estrutura verbal [...]. Como a Linguística é a ciência global da estrutura verbal, a Poética pode ser encarada como parte integrante da Linguística" (p. 119).

Por fim, é nesse texto que o linguista propõe a famosa "função poética" que, dentre as outras funções da linguagem, é aquela cujo enfoque está "na mensagem por ela própria" (p. 128). Na poesia, a função poética se sobrepõe às demais funções da linguagem (p. 132). Tal função "projeta o princípio de equivalência do eixo da seleção sobre o eixo de combinação" (p. 130). Em outras palavras, "um poema combina, no eixo sintagmático, elementos que, na base de suas equivalências naturais, constituem classes ou paradigmas de equivalência" (LEVIN, 1975, p. 51).

Nas suas muitas análises de poemas, Jakobson (1962, 1990, 2004, s.d) procurou evidenciar de que modo as relações estabelecidas entre os vários elementos linguísticos contribuem para a significação geral do texto.

Nos Ensaios, Greimas reconhece que os estudos jakobsonianos - com destaque para a análise do poema "Les chats", de Baudelaire, realizada em parceria com Lévi-Strauss (1962) - constituem a base para os trabalhos apresentados na obra (GREIMAS, 1975, p. 15):

Assim, a análise dos Chats, de Baudelaire, proposta por R. Jakobson e C. Lévi-Strauss, constitui, de per si, uma data a que se refere o conjunto de estudos concretos desta coletânea, como representando uma hipótese de trabalho e um modus operandi exemplar.

A ideia de Jakobson acerca da interação entre os diversos elementos constitutivos dos poemas pode também ser percebida em outros trechos de seus escritos, como, por exemplo, no que destacamos a seguir (JAKOBSON, 2004, p. 70):

Fenômenos como a interação entre as equivalências e discrepâncias sintáticas, morfológicas e léxicas, como os diferentes tipos de contiguidades semânticas, similaridades, sinonímias e antonímias, [...] todos esses 
fenômenos estão a exigir uma análise sistemática, análise esta indispensável à compreensão e interpretação dos vários mecanismos gramaticais da poesia.

Assim, Jakobson propõe que a análise dos poemas deve procurar levantar tanto os paralelismos e as simetrias quanto os contrastes entre as classes gramaticais, ${ }^{5}$ entre os fonemas, os morfemas, as isotopias, a sintaxe, as rimas, os versos, o ritmo, a distribuição das estrofes. Coquet (1975, p. 37) vai ao encontro de Jakobson quando afirma que a análise de um poema deveria revelar os paralelismos ou rupturas gramaticais, fônicos, prosódicos e/ou semânticos e as relações entre eles. As análises jakobsonianas sempre procuraram descrever qual a funcionalidade discursiva dos fatos gramaticais.

Além da imensa contribuição de Roman Jakobson, não podemos deixar de mencionar os estudos de Ferdinand de Saussure sobre os anagramas, ${ }^{6}$ certamente precursores dos estudos semiolinguísticos de poesia.

$\mathrm{Na}$ linguagem corrente, um anagrama é simplesmente a "transposição de letras de palavra ou frase para formar outra palavra ou frase diferente". ${ }^{7}$ Um exemplo corriqueiro seria AMOR como anagrama de ROMA. Neste trabalho, porém, não é essa a noção de anagrama que utilizamos, mas sim aquela proposta por Zilberberg (2006), na esteira dos estudos de Ferdinand de Saussure sobre poesia.

Foi no início do século XX, quando estudava os versos saturninos (uma forma de versificação latina), que Saussure percebeu que algumas regras os regem no que diz respeito a sua organização fonético-fonológica. Tais estudos só foram publicados postumamente, nos anos 70, com comentários de Jean Starobinski (1971), na obra Les mots sous les mots.

Duas constatações principais são feitas a partir desses estudos saussurianos: a primeira tem a ver com o fenômeno da aliteração e a segunda, com a existência de "hipogramas" ou "palavras-tema" nos textos poéticos. Com relação à primeira, citamos Starobinski (1978, p. 7):

Ele (Saussure) percebe primeiro a lei de 'acoplamento', que pretende que seja redobrado, no interior de cada verso, o emprego de toda vogal e de toda consoante utilizadas uma primeira vez. A aliteração deixa de ser um eco ocasional; repousa numa duplicação consciente e calculada.

A redundância, a repetição dos fonemas dentro de um mesmo verso, notadas por Saussure, foram também descritas posteriormente por Cohen (1982, p. 56): "O verso (versus), é na essência um retorno, um discurso que repete total ou parcialmente a mesma figura fônica". A "figura fônica" de Cohen seria, então, o que Zilberberg chamou de "núcleo endogramático" (2006, p. 186) ou o hipograma saussuriano.

As palavras-tema (ou hipogramas) são aquelas cujos sons servem de base para o restante do verso ou do poema: "o poeta atualiza na composição do verso o material fônico fornecido por uma palavra-tema" (STAROBINSKI, 1978, p. 9). Saussure chega até mesmo,

\footnotetext{
${ }^{5}$ Cf. Jakobson (2004, p. 74): "Entre as categorias gramaticais utilizadas em paralelismos e contrastes estão, com efeito, todas as classes de palavras, variáveis e invariáveis, as categorias de número, gênero, caso, grau, tempo, aspecto, modo e voz, as classes de concretos e abstratos, de animados e inanimados, os nomes próprios e comuns, as formas afirmativas e negativas, as formas verbais finitas e infinitas, pronomes e artigos definidos e indefinidos e os diversos elementos e construções sintáticos".

${ }^{6}$ Jakobson (s.d., p. 199, tradução nossa) afirma: "Nessa pesquisa, Saussure abre oportunidades sem precedentes para o estudo linguístico da poesia”.

${ }^{7}$ Conforme o Dicionário Houaiss da Língua Portuguesa. Disponível em: <http://houaiss.uol.com.br/busca.jhtm?verbete=anagrama\&stype=k>. Acesso em 20 mar. 2008.
} 
num segundo momento, a estender as suas reflexões à poesia védica e chega a pensar se existiria um padrão indo-europeu de poesia.

Os anagramas são, pois, a transposição dos sons ou módulos-fônicos presentes na palavra-tema, para outras partes dentro do poema. Trata-se das combinações de fonemas e não apenas de letras. Outro conceito tratado por Saussurre foi o de "paragrama", que nada mais é que "um anagrama escrito em descontinuidade" (LOPES, 1997, p. 182). Tomemos como exemplo um poema de Manuel Bandeira (1993, p. 205): "Nova Poética".

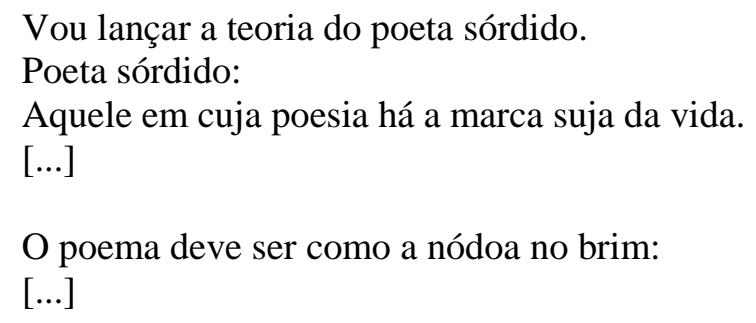

No primeiro verso, o narrador anuncia que lançará a teoria do poeta "sórdido" e, em seguida, passa a descrever esse tipo de poeta. No verso em destaque, encontramos o adjetivo "sórdido" anagramatizado (ALMEIDA, p. 152, 2007) em descontinuidade, ou seja, trata-se de um paragrama:

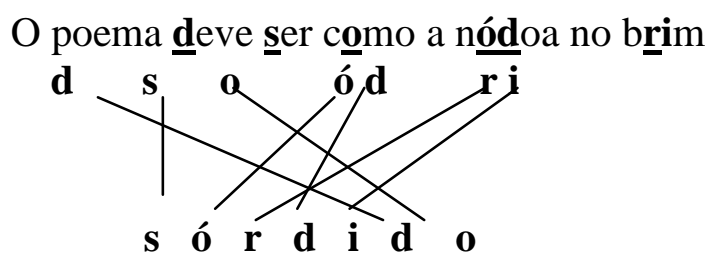

Figura 1 - Exemplo de paragrama

Então, o poema deve ser, assim como o poeta, sórdido.

Conforme dissemos anteriormente, o endograma de Zilberberg seria análogo à palavra-tema de Saussure, mas, para este, a unidade considerada era apenas uma palavra, ao passo que o endograma pode ser de qualquer grandeza: uma palavra, um verso, um sintagma, uma sequência de fonemas, etc. O núcleo endogramático existe, portanto, quando uma dessas grandezas se repete ao longo de um poema, mostrando, segundo Zilberberg (2006), que a função anagramática (ou aliterativa) não é, nos termos de Hjelmslev, apenas intensa, local, pontual, mas pode ser também global, ou seja, extensa.

Jakobson (2004, p. 82-83) também revisitou a teoria saussuriana ao dizer que um poema deve apresentar simetrias fonéticas em torno de uma palavra que apareceu anteriormente e, em outra passagem, afirma:

[...] o texto está entretecido destas manifestações típicas do paralelismo, como, por exemplo, a repetição de certas palavras ou de grupos inteiros de palavras, ou a variação de certas palavras, ou seja, o aproveitamento de diversos membros de um paradigma ou então de diferentes formações de uma mesma raiz [...] (2004, p. 135). 
Em qualquer um desses autores, portanto, fica clara a posição de que sempre há uma parte do poema (uma palavra, um bloco sonoro, um sintagma, etc.) que convoca outras partes do poema, que é nelas ecoada, funcionando como uma espécie de matriz geradora. A "função aliterativa" proposta por Zilberberg (2006, p. 185), que reproduzimos na figura abaixo, ilustra o fenômeno:

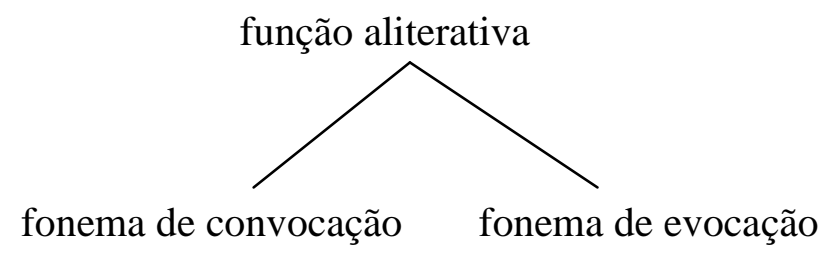

Figura 2 - Função aliterativa

Para Zilberberg (2006, p. 186), o endograma é a grandeza que contém os fonemas de convocação. Por sua vez, a grandeza que contém os fonemas de evocação é designada por exograma. Temos, pois, que o anagrama é função do endograma mais o exograma.

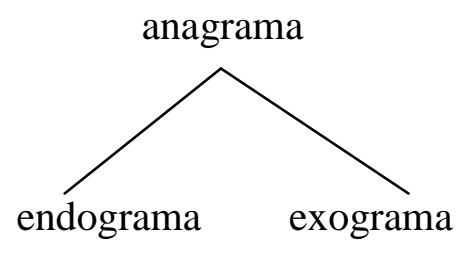

Figura 3 - Anagrama

O parágrafo a seguir (ZILBERBERG, 2006, p. 256) resume e explica de maneira bastante clara a hipótese anagramática:

A hipótese anagramática corresponde, resumidamente, a ver no lexema anagramatizado um endograma que concentra os fonemas (ou, eventualmente, os traços) de convocação, em relação com um exograma que faz propagar os fonemas do endograma, os quais se tornam, por isso, fonemas (ou traços) de evocação: ou ainda, de acordo com a terminologia saussuriana, contravogais e contraconsoantes.

Principalmente no caso da ocorrência dos paragramas, podemos considerar, de acordo com Lopes (1997, p. 184), que a teoria anagramática de Saussure contém a ideia de que existem dois textos possíveis no poema paragramático: um primeiro texto explícito, apreendido pela leitura linear, e um segundo texto implícito, paragramático, recuperável pela leitura tabular, que condensa alguma ideia essencial ao poema ou ao trecho em questão.

A hipótese anagramática está pautada, obviamente, na elaboração fonética do verso, importante constituinte dos poemas, mas não o único. E é aí que retornamos às Disponível em: http://seer.fclar.unesp.br/casa 
propostas de Jakobson, que considera, como já vimos, os outros níveis linguísticos como importantes para a geração do sentido: "Sem dúvida alguma, o verso é fundamentalmente uma 'figura de som' recorrente. Fundamentalmente, sempre, mas nunca unicamente" (JAKOBSON, 1969, p. 144, grifo nosso).

Sobre essa interação entre os diversos elementos linguísticos, cabe ainda citar Coquet (1975, p. 37) quando ele diz que, em um poema, num mesmo lugar de uma sequência, "podem se encontrar e se somar categorias de nível linguístico diferente, fônicas, gramaticais, semânticas, etc.", o que seria análogo à ideia de "acoplamentos" proposta por Levin (1975). Coquet ressalta, ainda, que o texto poético seria formado tanto numa dimensão horizontal, como, principalmente, numa direção vertical, "já que os níveis linguísticos empilham-se uns sobre os outros e são eco uns dos outros" (COQUET, 1975, p. 37).

A "soma" e o "empilhamento" de Coquet, remetem à ideia de uma concentração. Também o fazem a figura de um "acoplamento", proposta por Levin, a noção de "palavra-tema" de Saussure, o "texto paragramático" citado por Lopes, o "foco da mensagem em si mesma", na função poética de Jakobson, enfim, todas as explicações lançadas para tentar definir o objeto poético carregam essa noção. Tal concentração está sempre em jogo paralelamente a uma difusão. É nessa tensão que se estabelece, pois, o discurso poético, uma vez que a concentração estaria justamente na acumulação, no "empilhamento" de diversos elementos linguísticos, de níveis diferentes num mesmo "ponto" do poema. A difusão, por sua vez, seria a quantidade, a multiplicação desses elementos. A mesma ideia pode ser vista quando se trata de uma redundância, de uma repetição, como, por exemplo, na aliteração, na qual um mesmo elemento (fonema ou traço distintivo) se repete. No fato de ser um mesmo elemento ou poucos elementos reside a concentração; na repetição (no número de vezes que um elemento se repete) reside a difusão. Mesmo quando há um relacionamento entre partes diferentes do poema, isso se verifica, pois são várias partes (tendência à difusão) se voltando para um fechamento, uma reiteração dos mesmos elementos (concentração).

Seguindo a terminologia de Claude Zilberberg, no âmbito da chamada "semiótica tensiva", ${ }^{8}$ concentrado e difuso ${ }^{9}$ são extremos de um mesmo intervalo na dimensão que se chama de "eixo da extensidade". ${ }^{10}$ O poema, porém, vai "anular" essa oposição, no sentido de que esses dois regimes funcionam juntos na constituição do texto. É nesse entrecruzamento que estariam os textos considerados poéticos.

\section{Análise do poema "O prestidigitador"}

Um poema nunca está acabado, somente abandonado.

(Paul Valéry).

Ao longo de toda a literatura brasileira, desde a época colonial até os dias atuais, é possível encontrar metapoesia. ${ }^{11}$ A obra de Paulo Henriques Britto está repleta desses poemas que falam do próprio fazer poético, do próprio ato de escrever. É um desses textos

\footnotetext{
${ }^{8}$ Fontanille; Zilberberg (2001, p. 19).

${ }^{9}$ Zilberberg (2004).

${ }^{10} \mathrm{O}$ interesse em utilizar a abordagem tensiva para situar o texto poético reside no fato de que seus princípios podem dar conta tanto das questões do plano do conteúdo, quanto do plano da expressão.

${ }^{11}$ Brandão (1992).
} 
que submetemos à análise no momento: "O prestidigitador", metapoema de abertura do livro Trovar Claro, de $1997 .^{12}$ Ele apresenta o tema da escritura, do ato de escrever e fala da atitude do poeta frente à obra que compõe. Segue a transcrição do texto:

\section{O prestidigitador ${ }^{13}$}

1. Este papel que se oferece virgem

2. ao bel-prazer da pena e tinta

3. é todo teu, só teu, como não é,

4. nem nunca foi, a tua vida.

5. A gozosa vertigem dos começos -

6. esse friozinho bom no estômago -

7. aqui encontra lastro, ainda que tênue,

8. na realidade tão incômoda.

9. E se esta página inaugural

10. negar-te a façanha de um verso,

11. um gesto rápido há de restaurar

12. a virgindade do caderno.

13. As vértebras flexíveis da espiral

14. não vão guardar nenhum vestígio

15. (como fazem as lombadas traiçoeiras)

16. deste pequeno infanticídio.

17. Somente a nova página primeira

18. testemunhou a recaída.

19. Tenta outra vez: Este papel, etc.

20. (Restam noventa e nove ainda).

Uma leitura preliminar já é suficiente para que percebamos o caráter metalinguístico desse texto. Existem figuras que constituem a isotopia do escrever, tais como: "papel", "verso", "pena", "tinta”, "página", "caderno", "espiral”. Aqui, trata-se do processo de escrever em oposição à obra já criada. No processo de escrever, pode haver mudanças conforme indicam (grifo nosso) "vértebras flexíveis da espiral" (verso 13), "restaurar" (verso 11), "nova página primeira" (verso 17) - e no livro pronto, não - conforme sugere o verso 15: "(como fazem as lombadas traiçoeiras)".

Tal mudança é euforizada ao longo do texto, mas não se trata de qualquer mudança, e sim de uma mudança total, um recomeço. Há uma euforização do início, do começo, como podemos perceber pelos versos 5 e 6 (grifo nosso): "A gozosa vertigem dos começos / esse friozinho bom no estômago".

É possível pensar, aqui, em termos da aspectualidade que perpassa o poema. $\mathrm{O}$ aspecto vem sendo estudado pela Linguística há bastante tempo e foi, mais recentemente, incorporado pelos estudos semióticos do discurso (ALMEIDA, 2008). A Linguística o define como a maneira de ser da ação, ou como um ponto de vista sobre um processo no que diz

\footnotetext{
${ }^{12}$ Em tal livro ocorre a "presença ostensiva do discurso metalinguístico" (MASSI, 1997, orelha).

13 "Prestidigitador" é um ilusionista. O vocábulo é utilizado como título do poema como uma metáfora para o poeta que ilude, finge (lugar-comum em literatura).
} 
respeito a sua duração. Camara Jr. (1977, p. 141) nos explica esse conceito com o seguinte exemplo:

Distingue-se, por exemplo, uma ação que principia, como em partir, uma que termina como em chegar, uma que se desdobra, sem alusão ao início ou ao fim como andar, viajar, uma que se repete, como em saltitar, etc.

A semiótica, ainda que se abstenha de descer às minúcias da aspectualidade nesta ou naquela língua específica, estende a noção de aspecto para além da temporalidade: à espacialidade, à actorialidade e à axiologia, de acordo com Bertrand (2003, p. 416). Essa noção também é estendida, na medida em que os estudos sobre o aspecto realizados pela Linguística são geralmente relacionados ao verbo, e a semiótica postula que o aspecto pode incidir sobre enunciados inteiros (frases, parágrafos, etc.) e também sobre outras classes gramaticais. Considera-se que os processos são caracterizados pelos semas ${ }^{14}$ duratividade ou pontualidade, perfectividade ou imperfectividade, incoatividade ou terminatividade. Sintagmaticamente, ${ }^{15}$ os semas incoatividade, duratividade e terminatividade formam uma categoria aspectual. É o que mostra a figura a seguir (BARROS, 2001, p. 91):

$\begin{aligned} & \text { incoativo } \\ & \text { (pontual) }\end{aligned}$
$\begin{gathered}\text { durativo } \\ \text { (descontínuo } \\ \text { ou contínuo) }\end{gathered}$$\rightarrow \quad \begin{gathered}\text { terminativo } \\ \text { (pontual) }\end{gathered}$

Figura 4 - Semas aspectuais

Ora, no poema que analisamos, há um predomínio de figuras que contêm o sema "incoatividade", visto que sempre falam de começar e recomeçar. Essas figuras são: "papel virgem", "gozosa vertigem dos começos", "página inaugural", "restaurar a virgindade", "vértebras flexíveis" e "nova página primeira". A composição do poema também enfatiza o recomeço, pois, no penúltimo verso, depois dos dois pontos, vem exatamente o início do primeiro verso do poema. Podemos dizer que há uma aspectualização do comportamento do sujeito que sempre recomeça, sendo, portanto, um comportamento incoativo. Todavia, como o começo sempre se repete (é mais um recomeço do que simplesmente começo), podemos pensar também num aspecto iterativo.

Por outro lado, considerando o eixo paradigmático, encontramos a categoria perfectividade/imperfectividade, ou seja, acabado e inacabado. O poema que clama por um recomeço constante e prefere o processo de escrever à obra acabada (porque as lombadas são "traiçoeiras") é da ordem da imperfectividade. O uso do adjetivo "traiçoeiras" é fundamental para percebermos a avaliação negativa que o enunciador faz da obra acabada.

O sujeito deseja manter-se em conjunção com o ato de escrever. Não é a obra completa o seu objeto de valor, mas sim o processo de composição. Ele nunca completa o seu percurso; nunca chega, seguindo a terminologia de Zilberberg (2006), na continuação da parada, uma vez que sempre, antes disso acontecer, na parada da continuação, ele recomeça e continua, nunca chegando ao fim. A parada da continuação representa a parada do ato de escrever. Ocorrendo tal parada, o sujeito é levado à falta ou perda e, assim, tem que

\footnotetext{
${ }^{14}$ Cf. Dubois et al. (2004), p. 526: "o sema é a unidade mínima da significação (...) sinônimo de traço semântico $(\ldots)$ ".

${ }^{15}$ Para as noções de "sintagma" e "paradigma", Cf. Saussure (2002), p. 142. 
liquidar essa falta para recuperar a conjunção com seu objeto de valor ${ }^{16}$ (o processo de composição). Liquidando a falta, o sujeito se mantém num estado de relaxamento.

O quadrado semiótico a seguir (adaptado de TATIT, 2004, p. 200-201) nos ajuda a entender as relações entre paradas e continuações:

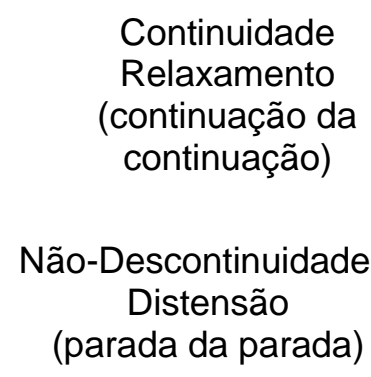

Continuidade

Relaxamento (continuação da

(parada da parada)

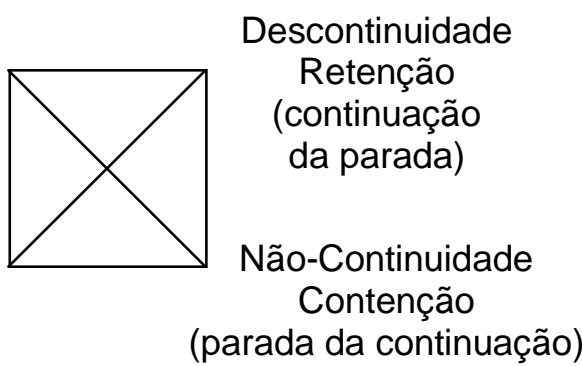

(parada da continuação)

Figura 5 - Quadrado semiótico tensivo

Essa oposição entre o processo de escrever e o produto pronto, obra acabada, aparece em outros momentos no livro em que "O prestidigitador" está inserido, como, por exemplo nas séries "Dez exercícios para os cinco dedos" e "Sete estudos para a mão esquerda", já que tanto o "exercício" quanto o "estudo" podem ser vistos como um treino para algo; ambos carregam o traço de imperfectividade.

Dissemos anteriormente que o objeto de valor que o sujeito almeja é o ato de escrever; ele quer manter a conjunção com esse ato. Dissemos, ainda, que o poema estabelece uma oposição entre o ato de escrever e a obra já acabada. A partir da leitura da primeira estrofe (versos 3 e 4, que destacamos abaixo), a obra acabada pode ser identificada à "vida real":

1. Este papel que se oferece virgem

2. ao bel-prazer da pena e tinta

3. é todo teu, só teu, como não é, 4. nem nunca foi, a tua vida.

O poema é a única coisa que o enunciador crê poder controlar - "ao bel-prazer da pena e tinta" (verso 2). Ele pode recomeçar um texto sempre que quiser e não restarão vestígios, enquanto, na vida, tudo o que acontece fica, de alguma forma, gravado para sempre, e não há a possibilidade, segundo esse enunciador, de um total recomeço, sem vestígios. Da mesma maneira que, num livro, um recomeço não é possível, pois as "lombadas traiçoeiras" guardariam vestígios, na vida também não é, tendo em vista que sempre haveria lembranças ou vestígios do ocorrido. O estado de relaxamento do sujeito se dá, então, justamente quando ele sente que tem o controle da situação - "é todo teu, só teu" (verso 3) - e possibilidade de mudança. Esses são, portanto, os valores almejados pelo sujeito, num nível mais profundo.

Como o sujeito crê não poder entrar em conjunção com tais valores na sua "vida real", e como a realidade é "tão incômoda" (verso 8), ele encontra, no processo de escrever, uma maneira de liquidar essa falta.

\footnotetext{
${ }^{16}$ Cf. Tatit, 1997, p. 133.
} 
A tabela a seguir resume as principais oposições que explicitamos até o momento. Note-se que essas oposições perpassam os vários níveis da significação, indo do figural ao figurativo:

\begin{tabular}{|c|c|c|}
\hline \multicolumn{3}{|l|}{ Níveis do Percurso gerativo do sentido ${ }^{17}$} \\
\hline \multirow[t]{2}{*}{ Nível tensivo } & Euforia & Disforia \\
\hline & Relaxamento & Tensão \\
\hline \multirow[t]{2}{*}{ Nível aspectivo } & Incoatividade & Terminatividade \\
\hline & Imperfectividade & Perfectividade \\
\hline Nível diretivo (ou modal) & crer-poder-ser & crer-não-poder-ser \\
\hline \multirow[t]{2}{*}{ Nível juntivo (ou narrativo) } & Flexibilidade/mudança & Permanência \\
\hline & Controle da situação & $\begin{array}{l}\text { Descontrole da } \\
\text { situação }\end{array}$ \\
\hline \multirow[t]{2}{*}{ Nível discursivo } & Processo de escrever & $\begin{array}{l}\text { Obra completa } \\
\text { ("Vida") }\end{array}$ \\
\hline & $\begin{array}{l}\text { "papel virgem"; } \\
\text { "ao bel-prazer da pena e } \\
\text { tinta"; } \\
\text { "é todo teu, só teu"; } \\
\text { "gozosa vertigem dos } \\
\text { começos"; } \\
\text { "friozinho bom"; } \\
\text { "página inaugural"; } \\
\text { "verso"; } \\
\text { "restaurar"; } \\
\text { "virgindade"; } \\
\text { "caderno"; } \\
\text { "vértebras flexíveis"; } \\
\text { "não vão guardar } \\
\text { nenhum vestígio"; } \\
\text { "nova página primeira" } \\
\text { "Tenta outra vez" }\end{array}$ & $\begin{array}{l}\text { "como não é, / nem } \\
\text { nunca foi, a tua vida"; } \\
\text { "realidade tão } \\
\text { incômoda"; } \\
\text { "lombadas } \\
\text { traiçoeiras"; }\end{array}$ \\
\hline
\end{tabular}

Figura 6 - Oposições nos níveis do percurso gerativo do sentido

No que diz respeito ao plano da expressão, constata-se que em todas as 5 quadras há versos octossílabos e decassílabos, regularmente. Percebemos que há características tanto do plano da expressão quanto do plano do conteúdo que fazem dos versos pares um conjunto e dos versos ímpares outro. "Versos pares" opostos a "Versos ímpares" seriam, assim, uma categoria do plano da expressão que pode ser homologada a outras categorias (tanto da expressão quanto do conteúdo), evidenciando uma determinada estratégia de organização/composição do poema. Os versos pares têm, todos, oito sílabas, recaindo o acento nas de número 4 e 8 . Se os versos fossem divididos ao meio, veríamos que o que se aplica regularmente é um padrão $\cup \cup \cup \_/ \cup \cup \cup \ldots$ _. A única exceção quanto ao ritmo é o verso de número 10, que diz: "negar-te a façanha de um verso,", havendo aqui, portanto, uma

${ }^{17}$ Modelo do Percurso Gerativo do Sentido conforme sua reformulação proposta por Zilberberg (2006, p. 156). Disponível em: http://seer.fclar.unesp.br/casa 
relação entre expressão e conteúdo, visto que o único verso par que está fora do padrão rítmico de todos os outros é justamente o que fala em negar a façanha de um verso, ou seja, é aquele que traz consigo uma noção de defeito, de falha. Vemos aí uma convergência entre conteúdo e expressão, uma vez que o que se diz em uma dessas faces é o que se faz na outra.

No que diz respeito às rimas, todos os versos pares rimam entre si dentro de suas estrofes, sendo esta uma rima toante, ou seja, quando rimam as vogais tônicas. ${ }^{18}$ Observa-se também uma predominância de rimas graves (formadas por palavras paroxítonas). Vejamos abaixo a transcrição desses versos, destacando as sílabas acentuadas e também as rimas:

\begin{tabular}{|c|l|l|l|l|l|l|l|l|l|}
\hline Versos/sílabas & 1 & 2 & 3 & 4 & 5 & 6 & 7 & 8 & \\
\hline $\mathbf{2}$ & ao & bel & pra & zer & da & pe & na e & tîn & ta \\
\hline $\mathbf{4}$ & nem & nun & ca & foi & a & tu & a & vi & da \\
\hline $\mathbf{6}$ & es & se & frio & zi & nho & bom & no es & tô̂ & mago \\
\hline $\mathbf{8}$ & na & re a & li & da & de & tão & in & cô̂ & moda \\
\hline $\mathbf{1 0}$ & ne & gar & te a & fa & ça & nha & de um & vêr & so \\
\hline $\mathbf{1 2}$ & a & vir & gin & da & de & do & ca & dêr & no \\
\hline $\mathbf{1 4}$ & não & vão & guar & dar & ne & nhum & ves & tî́ & gio \\
\hline $\mathbf{1 6}$ & des & te & pe & que & no in & fan & ti & cí̂́ & dio \\
\hline $\mathbf{1 8}$ & tes & te & mu & nhou & a & re & ca & î́c & da \\
\hline $\mathbf{2 0}$ & res & tam & no & ven & ta e & no & ve a & inn & da \\
\hline
\end{tabular}

Já os versos ímpares são decassílabos. Todavia há uma exceção, o verso 15 , "como fazem as lombadas traiçoeiras", que tem 11 sílabas. Também aqui há uma relação entre expressão e conteúdo, pois o único verso do poema fora do padrão silábico é justamente aquele que fala das lombadas traiçoeiras, ou seja, da obra completa que, como já vimos, é disforizada pelo poeta.

Sendo o controle sobre as coisas um dos valores almejados pelo sujeito, justamente o verso que fala de algo que ele não pode controlar e não pode mudar sem deixar vestígios é aquele que é "traiçoeiro" porque trai alguma regra, ou seja, que está "fora de controle" com relação aos demais versos do poema.

Quanto ao ritmo, ele é muito variado nos versos ímpares, predominando as irregularidades. Irregulares são também as rimas desses versos. A seguir apresentamos esses versos destacando as sílabas acentuadas a fim de melhor demonstrar a irregularidade de que falamos:

\footnotetext{
${ }^{18}$ Goldstein (2002, p. 44) descreve os vários tipos de rima.
} 


\begin{tabular}{|c|l|l|l|l|l|l|l|l|l|l|l|}
\hline Versos/Sílabas & 1 & 2 & 3 & 4 & 5 & 6 & 7 & 8 & 9 & 10 & \\
\hline $\mathbf{1}$ & Es & te & pa & pel & que & se o & fe & re & ce & vir & gem \\
\hline $\mathbf{3}$ & é & to & do & teu, & só & teu, & co & mo & não & é, & \\
\hline $\mathbf{5}$ & A & go & zo & sa & ver & ti & gem & dos & co & me & ços \\
\hline $\mathbf{7}$ & a & qui & en & con & tra & las & $\begin{array}{l}\text { tro, } \\
\text { ain }\end{array}$ & da & que & tê & nue \\
\hline $\mathbf{9}$ & E & se es & ta & pá & gi & na & i & nau & gu & ral & \\
\hline $\mathbf{1 1}$ & um & ges & to & rá & pi & $\begin{array}{l}\text { do } \\
\text { há }\end{array}$ & de & res & tau & rar & \\
\hline $\mathbf{1 3}$ & As & vér & te & bras & fle & xí & veis & da es & pi & ral & \\
\hline $\mathbf{1 5}$ & co & mo & fa & zem & as & lom & ba & das & trai & ço & ei \\
\hline $\mathbf{1 7}$ & So & men & te a & no & va & pá & gi & na & pri & mei & ra \\
\hline $\mathbf{1 9}$ & Ten & ta ou & tra & vez: & es & te & pa & pel & et & cé & tera \\
\hline
\end{tabular}

Existem, ainda, outros contrastes entre os versos pares e ímpares. No plano fonológico, por exemplo, constatamos que, nos versos pares, há um predomínio de consoantes sonoras, enquanto, nos versos ímpares, predominam as consoantes surdas. Outro contraste é que sempre os começos de proposições são feitos nos versos ímpares (e são esses os únicos que começam com letras maiúsculas).

Com relação ao plano do conteúdo, verificamos que, de 10 versos ímpares, 6 deles apresentam figuras relacionadas à escrita contra apenas 3 versos dentre os pares. Além disso, os vocábulos que remetem à incoatividade e à mudança estão todos (com exceção de apenas uma palavra, "virgindade", no verso 6) nos versos ímpares: v.1: "virgem"; v.5: "começos"; v.9: "inaugural"; v.11: "restaurar"; v.13: "flexíveis"; v.17: "nova" e "primeira"; v. 19: "tenta outra vez".

Passando à observação das categorias gramaticais, percebemos que nos versos ímpares, a maioria dos substantivos são qualificados por um adjetivo: dos 12 substantivos presentes, 8 são ligados a adjetivos. Nos versos pares, por sua vez, a quantidade de adjetivos não é tão significativa, já que são apenas 3 para 14 substantivos. A tabela abaixo mostra essas ocorrências:

\begin{tabular}{|c|c|}
\hline Versos Pares & Versos ímpares \\
\hline "friozinho bom" & "papel virgem" \\
\hline "realidade incômoda" & "gozosa vertigem" \\
\hline "pequeno infanticídio" & "lastro tênue" \\
\hline & "página inaugural" \\
\hline & "gesto rápido" \\
\hline & "vértebras flexíveis" \\
\hline & "lombadas traiçoeiras" \\
\hline
\end{tabular}

Figura 7 - Versos pares versus versos ímpares 
Mais uma distinção interessante entre os versos pares e ímpares é que, nestes, todos os cinco pares de versos mantêm uma relação entre si, mesmo quando isolados do restante do poema. São maiores os acoplamentos encontrados nesses versos. No primeiro par, por exemplo, há uma relação entre sujeito (verso 1) e predicado (verso 3):

Este papel que se oferece virgem é todo teu, só teu, como não é,

A mesma relação é encontrada no par seguinte:

A gozosa vertigem dos começos

aqui encontra lastro, ainda que tênue,

$$
\begin{aligned}
& =>\text { Sujeito } \\
& =>\text { Predicado }
\end{aligned}
$$

No par de versos 9 e 11, a relação encontrada é de ordem semântica, ambos os versos comportando palavras com o sema /incoatividade/: v.9: "inaugural" e v.11: "restaurar". O par de versos 13 e 15 também apresenta uma relação semântica, mas dessa vez não há uma contiguidade, e sim uma oposição: "espiral" (flexível) versus "lombadas" (permanente). Por fim, os versos 17 e 19 são da ordem do recomeço tanto pela presença das palavras "nova" e "tenta", quanto pela repetição do início do poema, simulando um recomeço do próprio poema em questão: "Este papel".

Diferentemente, as duplas de versos pares não mantêm relações entre si. ${ }^{19}$ Os versos ímpares conseguem fazer algum sentido mesmo isolados dos pares. Estes últimos, por sua vez, quando isolados dos ímpares não se correlacionam; ficam parecendo versos soltos. Não encontramos nem ligações sintáticas, nem semânticas entre eles.

Ressaltamos ainda a ocorrência de 5 palavras da ordem da negatividade nos versos pares contra apenas 1 nos versos ímpares:

\begin{tabular}{|c|c|}
\hline Versos pares & Versos ímpares \\
\hline "nem" & \\
\hline "nunca" & \\
\hline "negar" & \\
\hline "não" & \\
\hline "nenhum" & \\
\hline
\end{tabular}

Figura 8 - Negativas

O quadro abaixo nos ajuda a visualizar o que acabamos de expor acerca da organização dos versos pares versus os versos ímpares.

\begin{tabular}{|c|c|}
\hline Versos pares & Versos ímpares \\
\hline Octossílabos & Decassílabos $^{20}$ \\
\hline Ritmo regular: acento nas sílabas 4 e $8^{21}$ & Ritmo irregular \\
\hline Rimas toantes e graves & Predomínio de irregularidade rímica \\
\hline
\end{tabular}

\footnotetext{
${ }^{19}$ Com exceção do par 14 e 16, onde um verso é complemento gramatical do outro.

${ }^{20}$ Com exceção do verso 15 , conforme exposto acima.

${ }^{21}$ Com exceção do verso 10 , que explicamos anteriormente.
} 
CASA, Vol.9 n.1, julho de 2011

\begin{tabular}{|c|c|}
\hline Predomínio de consoantes sonoras & Predomínio de consoantes surdas \\
\hline Poucos adjetivos & Muitos adjetivos \\
\hline- & Maioria das figuras relacionadas à escrita \\
\hline Meio de períodos & Início de períodos \\
\hline- & incoatividade; mudança \\
\hline Pares de versos não se relacionam & Pares de versos se relacionam \\
\hline Negatividade & - \\
\hline
\end{tabular}

Figura 9 - Versos pares versus versos ímpares

Gostaríamos, agora, de ressaltar uma série de ocorrências no plano fonéticofonológico que, apesar de nem sempre ligadas diretamente ao plano do conteúdo, mostram uma sofisticada disposição do plano da expressão. A primeira dessas ocorrências é o fato de aparecer em quatro das cinco estrofes alguma palavra com a sequência " $v+$ vogal $+r$ ", núcleo endogramático do poema:
v.1 virgem
v.5 vertigem
v.10 verso
v.12 virgindade
v.13 vértebras

Em outras ocorrências, vemos aparecer sílabas semelhantes a essas, aparecendo $\mathrm{v}+\mathrm{e}+$ consoante, sendo /e/ a vogal que aparece na maioria das ocorrências acima.
v.14
vestígio
v.19
vez

exemplo:

Percebemos, também, a existência de algumas rimas internas, como por

Estrofe 1: $\quad$ v.1: papel / v.2: bel

v.3: "é todo teu, só teu (...)"

Estrofe 2: $\quad$ v. 5 gozosa / v. 6 friozinho

v.7 encontra / lastro vogais /o/ e /a/:

Note-se que nas palavras que destacamos no verso 7 há um quiasmo entre as

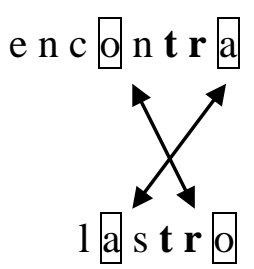

Disponível em: http://seer.fclar.unesp.br/casa 
CASA, Vol.9 n.1, julho de 2011

Figura 10 - "Quiasmo fonológico"

Há também um quiasmo das mesmas vogais nos versos 6 e 8, nas palavras que compõem a rima:

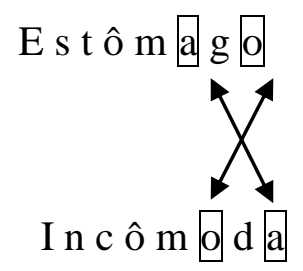

Figura 11 - "Quiasmo fonológico"

Aparece também o ditongo nasal grafado por -em ou -en em várias partes do poema - outro núcleo endogramático:

$\begin{array}{ll}\text { v.1 } & \text { virgem } \\ \text { v.4 } & \text { nem } \\ \text { v.5 } & \text { vertigem } \\ \text { v.7 } & \text { encontra } \\ \text { v.15 } & \text { fazem } \\ \text { v.17 } & \text { somente } \\ \text { v.19 } & \text { tenta } \\ \text { v. } 20 & \text { noventa }\end{array}$

Na estrofe 3, há a repetição da consoante /t/ nos versos 9 , 10 e 11. Todos possuem essa consoante na mesma sílaba poética. Na estrofe 4, destacamos a aliteração de fricativas no verso 13: "A $\$$ vértebras fle $\mathbf{x i}$ veis da espiral".

As situações acima podem ser vistas como atualizações da função aliterativa ou anagramática proposta por Saussure em seus estudos sobre poesia e os anagramas, que expusemos anteriormente.

O poema estudado revela uma atitude do sujeito-poeta frente ao processo de composição, sendo este último o seu meio de alcançar os valores desejados que não alcança na "vida real". O trabalho com figuras que sugerem uma aspectualidade incoativa/iterativa e imperfectiva foi um dos principais recursos utilizados pelo poeta para garantir o efeito de sentido pretendido e deixar clara a sua posição contra algo "acabado" e "permanente". Pudemos, também, levantar vários pontos do plano da expressão importantes para a significação global do texto, seja porque se ligam de alguma forma ao plano do conteúdo, seja porque revelam uma organização desse plano não como algo casual, mas sim como sistematicamente trabalhada.

\section{Conclusão}

Nosso trabalho consistiu na análise minuciosa do poema "O prestidigitador", de Paulo Henriques Britto, apoiando-se no modelo semiótico de orientação greimasiana. $\mathrm{O}$ 
estudo desse poema foi bastante proveitoso, permitindo-nos realizar uma descrição minuciosa dos seus planos da expressão e do conteúdo, ajudando a preencher a lacuna de estudos mais profundos acerca dos poemas de Britto e evidenciando as estratégias de que se vale o enunciador para engendrar os efeitos de sentido dos textos.

A descrição das imbricações entre os vários níveis do texto mostrou-se deveras relevante uma vez que revelou a engenhosidade literária por trás de sua construção. Assim, nossa análise permitiu testar as hipóteses das investigações estruturais de poesia que primam pela capacidade de evidenciar as similaridades e os contrastes que atuam na geração do sentido nos diversos níveis.

Ao cabo de nosso estudo, percebemos que tais imbricações não são casuais, mas sistematicamente trabalhados. A observação das peculiaridades fonético-fonológicas e gramaticais, bem como a observação da posição/distribuição dos versos no poema não é gratuita e é imprescindível para que compreendamos a sua grandeza estética, como explica Jakobson (2004, p. 82):

Tanto um cálculo de probabilidade quanto um trabalho acurado de comparação dos textos poéticos com outras espécies de mensagens verbais demonstram que as peculiaridades marcantes dos processos poéticos de seleção, acumulação, justaposição e distribuição das diversas classes fonológicas e gramaticais não podem ser consideradas acidentes desprezíveis regidos pela lei do acaso. Qualquer composição poética significativa, seja um improviso, seja fruto de longo e árduo trabalho de criação, implica escolha do material verbal, escolha esta orientada num sentido determinado [...]. Ele (o poeta) pode não ter consciência das molas mestras desse mecanismo, e isso ocorre com muita frequência. Porém, embora incapaz de especificar os procedimentos pertinentes à sua criação, o poeta - e também seu leitor receptivo - percebe a superioridade artística de um texto dotado desses componentes sobre um outro similar, mas privado deles.

Quisemos, ainda, na esteira de Jakobson, defender uma análise linguística de textos poéticos evidenciando a importância da interseção entre os dois campos de estudos (a Linguística e a Literatura). Sobre as relações entre essas duas áreas do conhecimento, retomamos uma vez mais as palavras do linguista (JAKOBSON, 1969, p. 162):

[...] compreendemos definitivamente que um linguista surdo à função poética da linguagem e um especialista de literatura indiferente aos problemas linguísticos e ignorante dos métodos linguísticos são, um e outro, flagrantes anacronismos.

Nossas análises partiram de um ponto de vista prioritariamente linguístico por acreditarmos que é o trabalho com a língua que faz de um poema um texto literário. Como diz Pietroforte (2008, p. 247):

[...] a poesia e a prosa são feitas, antes de tudo, de signos verbais e processos discursivos [...]. Há coerções históricas e sociais, sem dúvida, mas estas pertencem ao humano em todas as suas atividades discursivas, sejam elas literárias ou não. 
Nesse sentido, nossas reflexões ecoam as de Cohen (1974, p. 38, grifo nosso) que afirma que "O poeta é poeta não pelo que pensou ou sentiu, mas pelo que disse [...]. Todo seu gênio reside na invenção verbal"'.

\section{Referências bibliográficas}

ALMEIDA, D. Análise semiótica de 'Nova poética', de Manuel Bandeira. Todas as Letras revista de língua e literatura. São Paulo, Universidade Mackenzie, v.9, n.1, 2007. Disponível em: < http://www3.mackenzie.com.br/editora/index.php/tl/article/view/664/595>. Acesso em: 29 abr. 2009.

Semiótica e aspectualidade em poemas de Manuel Bandeira. Cadernos de Semiótica Aplicada, v.6, n. 2, 2008. Disponível em: <http://www.fclar.unesp. br/seer/index.php?journal=casa\&page=issue\&op=view\&path[]=244>. Acesso em: 29 abr. 2009.

BANDEIRA, M. Estrela da vida inteira. Rio de Janeiro: Nova Fronteira, 1993.

BALDAN. M. de L. O. G. Entre o som e o sentido: aspectos da poética de Roman Jakobson. 1994. Tese de Doutorado apresentada à Universidade de São Paulo (USP).

BARROS, D. L. P. de. Teoria do discurso: fundamentos semióticos. São Paulo: Humanitas, 2001.

BERTRAND, D. Caminhos da semiótica literária. Tradução Grupo CASA. Bauru: EDUSC, 2003.

BRANDÃO. R de O. Poemas sobre a poesia na literatura brasileira. 1992. Tese de Livre Docência apresentada à Universidade de São Paulo (USP).

BRITTO, P. H. Trovar claro. São Paulo: Companhia das Letras, 1997.

CAMARA JR., J. M. “Uma categoria verbal: o aspecto". In: . Princípios de

Linguística geral. Rio de Janeiro: Padrão, 1977.

COHEN, J. Introdução: objeto e método; O problema poético. In: Estrutura da linguagem poética. São Paulo: Cultrix, Edusp, 1974. Poesia e redundância. In: O discurso da poesia, n. 28. Coimbra: Almedina, 1982.

COQUET, J-C. Poética e Linguística. In: GREIMAS, A. J. Ensaios de Semiótica Poética. São Paulo: Cultrix, 1975.

Dicionário Houaiss. Disponível em: 〈http://houaiss.uol.com.br/busca.jhtm>.

DUBOIS, J. et al. Dicionário de Linguística. São Paulo: Cultrix, 2004.

FIORIN, J. L. Em busca do sentido: estudos discursivos. São Paulo: Contexto, 2008.

FONTANILLE, J. \& ZILBERBERG, C. Tensão e significação. Trad. Ivã Carlos Lopes; Luiz Tatit; Waldir Beividas. São Paulo: Discurso Editorial/Humanitas, 2001.

GOLDSTEIN, N. Versos, sons, ritmos. São Paulo: Ática, 2002.

GREIMAS, A. J. Du sens: essais sémiotiques. Paris, Seuil, 1970. (Org.). Ensaios de semiótica poética. São Paulo: Cultrix, 1975. 
GREIMAS, A. J. \& COURTÉS, J. Sémiotique: dictionnaire raisonné de la théorie du langage. Paris: Hachette, 1979.

Dicionário de semiótica. São Paulo: Cultrix, 1983.

HJELMSLEV, L. Prolegômenos a uma teoria da linguagem. São Paulo: Perspectiva, 2003.

JAKOBSON, R. \& LÉVI-STRAUSS, C. Les Chats de Charles Baudelaire. L'Homme. v. 2, 1962.

JAKOBSON, R. Linguística e poética. In: . Linguística e comunicação. São Paulo: Cultrix, 1969.

Poética em ação. São Paulo: Perspectiva, 1990.

. Linguística. Poética. Cinema. São Paulo: Perspectiva, 2004.

Questions de poétique. Paris: Seuil, [s.d.].

LEVIN, S. R. Estruturas linguísticas em poesia. São Paulo: Cultrix, Edusp, 1975.

LOPES, E. Cláudio, o artesão. In: Metamorfoses: a poesia de Cláudio Manuel da Costa. São Paulo: Editora UNESP, Fundação, 1997.

PIETROFORTE, A. V. S. O discurso da poesia concreta: uma abordagem semiótica. 2008. Tese de Livre Docência apresentada à Universidade de São Paulo (USP).

SAUSSURE, F. de. Curso de Linguística geral. São Paulo: Cultrix, 2002.

STAROBINSKI, J. Les mots sous les mots: les anagrammes de Ferdinand de Saussure. Paris: Gallimard, 1971.

As palavras sob as palavras: os anagramas de Ferdinand de Saussure. Trad. Carlos Vogt. São Paulo: Perspectiva, 1978.

TATIT, L. Musicando a semiótica: ensaios. São Paulo: Annablume, 1997.

Análise semiótica através das letras. São Paulo: Ateliê Editorial, 2001.

Abordagem do texto. In: FIORIN, J. L. (Org.). Introdução à Linguística I: objetos teóricos. São Paulo: Contexto, 2004.

ZILBERBERG, C. As condições semióticas da mestiçagem. In: CAÑIZAL, E. P \& CAETANO, K. E. (Orgs.). O olhar à deriva: mídia, significação e cultura. Trad. Ivã Carlos Lopes; Luiz Tatit. São Paulo: Annablume, 2004.

Razão e poética do sentido. Tradução de Ivã Carlos Lopes; Luiz Tatit; Waldir

Beividas. São Paulo: Edusp, 2006.

Recebido em: 10.03 .11

Aprovado em: 26.04.11 